\title{
Isolation, Screening and Optimization for Laccase production by Scytalidium lignicola pesante under submerged fermentation
}

\author{
Amanpreet K. Sidhu, Sonali B. Darade, Praneeta P. Bhavsar, \\ Vishwas B. Gaikwad and Sucheta N. Patil*
}

\author{
Department of Biotechnology, K.T.H.M College, Nashik, Maharashtra,India, India \\ *Corresponding author
}

\section{A B S T R A C T}

Ke y w o r d s
ABTS, Catalase,
Guaiacol, Laccase,
Media optimization,
Scytilidium
lignicola and
Submerged
fermentation

\section{Keywords}

ABTS, Catalase,

Guaiacol, Laccase, Media optimization, Scytilidium ignicola and Submerged ermentation
Twenty Five lignolytic fungi were isolated from decaying wood samples and were screened for the laccase production using guaiacol and ABTS as indicator compounds. The positive isolates were confirmed for the presence of laccase using Azure B and quantitative enzyme assay in presence of catalase using ABTS as substrate. Further laccase producing capacity of fungus was estimated in seven different media where Czapex Dox medium showed highest enzymatic activity of $17.2 \mathrm{U} / \mathrm{ml}$. Effect of carbon and nitrogen sources, initial $\mathrm{pH}$, inoculum size, incubation period, incubation temperature, inducer and inhibitor on laccase production was evaluated. The optimal $\mathrm{pH}$, incubation temperature, incubation period and inoculum size for the laccase production in submerged culture were found to be $\mathrm{pH} 6,30^{\circ} \mathrm{C}, 7$ days and $2 \mathrm{disc} / 100 \mathrm{ml}$ medium respectively. Sucrose and sodium nitrate were the most suitable carbon and nitrogen sources for laccase production. Out of the different inducers and inhibitors, the prominent induction was observed with $2 \mathrm{mM} \mathrm{CuSO}_{4}$ and $0.1 \%$ $\mathrm{MgSO}_{4}$ while sodium azide and formaldehyde inhibited the laccase production almost $94 \%$ and $74 \%$ respectively. Under the optimal condition the maximum laccase activity was determined to be $28.2 \mathrm{U} / \mathrm{ml}$ which is supposed to be 1.5 times higher than the unoptimized conditions.

\section{Introduction}

Laccases (benzenediol: oxygen oxidoreductase, (EC1.10.3.2) are muti-copper oxidases widely distributed among plants, insects and fungi (Sidhu et al.,2014). Laccase reduce molecular oxygen to water and simultaneously perform one-electron oxidation of various substrates such as diphenols, methoxy-substituted monophenols and aromatic and aliphatic amines. (Elsayed et al., 2012). Unlike lignin peroxidases and manganese peroxidase, laccase is capable of catalyzing the oxidation of organic compounds in the absence of $\mathrm{H}_{2} \mathrm{O}_{2}$ (Ding et al., 2012).The peroxidases have the highest redox potential, being able to catalyze directly the oxidation of non-phenolic compounds. However, the use of oxygen (a non-limiting electron acceptor) by the laccases makes these enzymes more adequate for industrial and environmental applications (Zouari-Mechichi et al., 2006). Due to their low substrate specificity and strong oxidative abilities, laccases have a number of industrial applications including biopulping, prevention of wine decolouration, detoxification of environmental pollutants, textile dye 
bleaching, enzymatic conversion of chemical intermediates and the production of valuable compounds from the lignin (Thurston 1994; Patrick et al., 2009).

Microbes that produce laccases have been screened for either on solid media containing coloured indicator compounds that enable the visual detection of the laccase production or with liquid cultivations monitored with activity measurements (Kiiskinen et al., 2004). Usually there are several compounds that have been used as substrates by spectrophotometry methods such as 2,2'azinobis-(3-ethylbenzthiazoline-6-sulfonate) (ABTS) (Majolagbe et al., 2012), Syringaldazine (Iyer et al., 2003; Saito et al., 2003), guaiacol, o-dianisidine (Li et al., 2008) and 2,6-dimethoxyphenol (Abdulla et al., 2000). Although many different substrates are available for assaying of laccases but ABTS is considered as a most sensitive among all tested compounds to evaluate the activity of laccase (Li et al., 2008). Discovery of noval laccases with different substrate specificities and improved stabilities is very important for industrial applications, besides developing an effective high yield and economic production medium enhances its utility (Desai et al., 2011).

In this study, we isolated a new fungus from Igatpuri, Nashik, India. The fungus produces large amount of laccase, under the culture conditions. We described here, the confirmatory tests for establishing laccase production and optimization of the parameters to improve the laccase productivity under lab conditions.

\section{Materials and Methods}

\section{Isolation of laccase producing microorganisms}

Twenty seven samples were collected in sterile tubes from the decaying wood and tree bark scrapings of live trees, from the forests of Igatpuri, Kasara and Bhandardara around Nashik in Maharashtra, India. Sample collection was done during monsoon season in Maharashtra as it was easy to see the growing fungi on the tree bark. Samples were subjected to isolation by standard serial dilution method and inoculated on Potato Dextrose Agar (PDA) medium supplemented with $0.01 \% \mathrm{~W} / \mathrm{V}$ peptone, $0.001 \% \mathrm{~W} / \mathrm{V}$ yeast extract and 20\% W/V glucose (Desai et al., 2011; Alfarra et al., 2013; Singh et al., 2013). The isolated colonies thus obtained were maintained on PDA agar at $4^{\circ} \mathrm{C}$ for subsequent use as inoculums and subcultured after every 15 days. Twenty five strains were isolated and were designated as $\mathrm{DF}_{1}$ to $\mathrm{DF}_{25}$.

\section{Screening and validation of laccase production}

All the isolated and subcultured fungal strains were inoculated on Petri plates containing PDA medium, amended with $0.02 \%$ guaiacol (Fu et al., 2013), 0.1\% 2,2'-azinobis-(3ethylbenzthiazoline-6-sulfonate) (ABTS) and $0.01 \%$ Azure B (Alfarra et al., 2013) each separately. Development of dark brown color around the colonies on guaiacol and of dark green to purple color on ABTS containing medium indicates presence of laccase being produced by the fungus. While absence of clear zone on the Azure B containing plates is confirmation of extracellular laccase production, as it is the substrate of peroxidases.

\section{Laccase activity assay}

Czapex Dox medium was used as liquid fermentation media for quantitative estimation of enzyme activities from the selected strains. Two disc of peripheral growing fungal isolates ( $8 \mathrm{~mm}$ in diameter) were inoculated aseptically in the broth. The culture was incubated at $25^{\circ} \mathrm{C}$ for 7 days. At the end of each growth period, inoculated tubes were collected and centrifuged at 5000 
rpm for 5 min. at $4^{\circ} \mathrm{C}$ (Sidhu et al., 2014). The filtrate was tested for laccase enzymes activity as follows and enzyme activity was expressed in $\mathrm{U} / \mathrm{ml}$.

Catalase $(1,000 \mathrm{U} / \mathrm{ml})$ was added to the assay solution and incubated for $1 \mathrm{~h}$ at $37^{\circ} \mathrm{C}$ to remove the possible effect of $\mathrm{H}_{2} \mathrm{O}_{2}$ produced by the fungus (Sheikhi et al., 2012). Laccase activity was determined spectrophotometrically at $420 \mathrm{~nm}\left(€ 420=36,000 \mathrm{M}^{-1} \mathrm{~cm}^{-1}\right)$ with 2,2'-azinobis-(3-ethylbenzthiazoline-6sulfonate) (ABTS) as a substrate. The assay mixture contained $150 \mu \mathrm{L}$ of $0.5 \mathrm{mM}$ substrate (ABTS), $2.7 \mathrm{~mL}$ of $0.1 \mathrm{M}$ sodium acetate buffer of $\mathrm{pH} 4.5$ and $150 \mu \mathrm{L}$ of culture supernatant and was incubated for $5 \mathrm{~min}$. Absorbance was read at $420 \mathrm{~nm}$ in a spectrophotometer against a suitable enzyme and substrate blank. The activity was defined as the amount of enzyme that oxidized 1umol of ABTS per min and the activities were expressed in $\mathrm{U} / \mathrm{ml}$. All spectrophotometric measurements were carried out using a UVVis spectrophotometer (Systronics, PC based double beam spectrophotometer 2202). All assays were carried out in triplicate (Bourbonnais et al., 1995; Moore et al., 2011; Zhu et al., 2016).

\section{Screening of different liquid media for laccase production}

Different media like malt extract broth, potato dextrose broth, Czapeck Dox, Sabrourd's Medium, Yeast glucose broth, (Amrutha and Abhijit, 2015) Basal liquid Medium (Saparrat et al., 2007; Rajendran et al., 2011), Rose Bengal medium (Christie and Shanmugam, 2012) were screened for laccase production. Medium showing highest enzyme production was further used for optimization experiments.

Optimization of carbon and nitrogen sources for laccase production

Czapeck Dox medium has shown superior results over all the other media screened for laccase production. To investigate the best carbon source, the sucrose in the Czapek Dox media was replaced with other carbon resources including fructose, maltose (Prasher et al., 2015), glucose, galactose, lactose and cellulose (zhu et al., 2016). Effect of different organic and inorganic nitrogen sources like malt extract, urea (Elsayed et al., 2012), peptone (Kenkebashvili et al., 2012), ammonium nitrate and ammonium chloride (Prasher et al., 2015) were evaluated by replacing sodium nitrate from Czapek Dox media. $100 \mathrm{ml}$ Media with above carbon and nitrogen sources was prepared in Erlenmeyer flask $250 \mathrm{~mL}$ and autoclaved. Two disc $(8 \mathrm{~mm}$ in diameter) of a 5 days old culture were inoculated in this media and incubated at \pm 25 ${ }^{\circ} \mathrm{C}$ for 7 days. Control with standard Czapek Dox media was run in parallel.

\section{Optimization of other parameters for laccase production}

The initial $\mathrm{pH}$ of the medium was adjusted from $\mathrm{pH} 2$ to $\mathrm{pH} 8$ at the interval of 1 unit using $0.1 \mathrm{M} \mathrm{HCl}$ and $0.1 \mathrm{M} \mathrm{NaOH}$ to study its effect on laccase production. Temperature optimization was done by incubating the culture flasks at temperature ranging from 0 to $50^{\circ} \mathrm{C}$ (Mahmoud et al., 2013). To study the effect of inoculum size on laccase production, number of discs ( $8 \mathrm{~mm}$ in diameter) inoculated were varied form 1-5. 100ml of Czapek Dox medium with above mentioned variations was prepared and autoclaved. Except the experiment conducted to check the effect of inoculum size, to remaining flasks two discs ( $8 \mathrm{~mm}$ in diameter) of a 5 days old culture were inoculated and culture flasks were incubated at $\pm 25^{\circ} \mathrm{C}$ for 7 days.

In order to find the optimal time of incubation for the maximum laccase production $100 \mathrm{~mL}$ Czapek Dox media was prepared and autoclaved. To this two discs $(8 \mathrm{~mm}$ in diameter) of a 5 days old culture were 
inoculated and incubated at $\pm 25^{\circ} \mathrm{C}$ for 10 days. The culture harvested every day from day 2 to day 10 and was used to determine enzyme activity (Kumar et al., 2016).

\section{Effect of inducers and inhibitors on laccase production}

Different inducers were investigated for their capacity to increase laccase production such as ABTS $(0.6 \mathrm{mM})$, guaiacol $(1 \mathrm{mM}), \mathrm{CuSO} 4$ $(2 \mathrm{mM}), \quad \mathrm{MgSO}_{4}(0.1 \%)$ and tannic acid $(0.2 \mathrm{mM})$. Different inhibitors such as sodium azide, EDTA (Ethylene diamine tetraacetic acid) (Mahmoud et al., 2013; Nadeem et al., 2014), formaldehyde and L-cysteine at the concentration of $1 \mathrm{mM}$ were added in the medium to evaluate the inhibition of enzyme production. 100ml of Czapek Dox medium devoid of $\mathrm{MgSO}_{4}$ with above mentioned inducers was prepared, as $\mathrm{MgSO}_{4}$ is also considered as one of the inducer. $100 \mathrm{ml}$ of Czapek Dox medium consisting of above listed inhibitors was also prepared and autoclaved. To this sterilized medium two discs (8mm in diameter) of a 5 days old culture were inoculated and incubated at \pm $25^{\circ} \mathrm{C}$ for 7 days. Czapek Dox media without the addition of any inducer and inhibitor was run in parallel. Further effect of different concentrations of $\mathrm{CuSO} 4(0.5 \mathrm{mM}, 1.0 \mathrm{mM}$, $1.5 \mathrm{mM}, 2.0 \mathrm{mM}, 3.0 \mathrm{mM}, 4.0 \mathrm{mM}$ and $5.0 \mathrm{mM})$ and $\mathrm{MgSO}_{4}(0.02,0.04,0.06,0.08,0.1,0.12,0.14$ and $0.16 \%$ ) was also evaluated in the similar way.

\section{Enzyme production under optimized conditions}

In order to determine the combined effect of the above mentioned parameters and to maximize the laccase production, Czapek Dox medium with all the optimized parameter was prepared. The medium was sterilized and inoculated with two discs (8mm in diameter) of a 5 days old culture and was incubated at \pm $25^{\circ} \mathrm{C}$ for 7 days. The enzyme activity was estimated at the end of the incubation period and was compared with the unoptimized Czapek Dox medium.

\section{Results and Discussion}

\section{Isolation and screening of fungal culture for laccase production}

Twenty five different fungal isolates were isolated from the decaying wood scrapings which were named as $\mathrm{DF}_{1}$ to $\mathrm{DF}_{25}$. All the isolates were subcultured and screened for laccase activity on Czapek Dox medium with $0.02 \%$ guaiacol. Laccase enzyme react with guaiacol to give reddish brown color product, out of the above 25 isolates 12 isolates were found to be positive.

All the positive isolates were evaluated quantitatively by performing enzyme assay using ABTS as the substrate of the enzyme. The crude enzyme extract was treated with catalase to degrade any endogenously produced hydrogen peroxide $\left(\mathrm{H}_{2} \mathrm{O}_{2}\right)$, this helps to eliminate any false positive results due to the presence of peroxidases.

Out of the 12 positive isolates only two isolates $\left(\mathrm{DF}_{8}\right.$ and $\left.\mathrm{DF}_{12}\right)$ showed prominent laccase activity which is $16.2 \mathrm{U} / \mathrm{ml}$ and $12.61 \mathrm{U} / \mathrm{ml}$ respectively. The positive isolates were separately grown for secondary screening on Czapek Dox medium containg $0.1 \%$ ABTS and $0.01 \%$ Azure B. Both the isolates showed characteristic blue color zone surrounding the colonies due to the oxidation of ABTS. ABTS assay is considered to be more efficient assay for screening of laccase producer as far as cost, time and method is concerned (Kumar et al., 2016). None of the two isolates showed zone on the Azure B containing plates. According to Kumar et al., (2016) several fungi which secrete lignin peroxidase and manganese peroxidase have ability to decolorize or degrade Azure B dye. 
But laccase enzyme cannot decolorize Azure B. Presence of laccase is sometimes confused with the presence of peroxidase as both are capable of oxidizing variety of phenolic indicators but absence of clearance zone on Azure B containing plate is confirmation of the laccase production.

Out of the Twenty five isolated fungi, isolate no. DF8 and DF12 were confirmed for the production of laccase by both qualitative plate assay and quantitative enzyme assay. Both the isolates were characterized on the basis of morphological characters from Agharkar Research Institute. They were identified as Scytalidium lignicola pesante and Curvularia pallenscens Boedijn. Further work was carried out on Scytalidium lignicola pesante, as it was found to be maximum producer of the laccase enzyme over the other isolate in quantitative enzyme assay.

\section{Optimization of different media}

Different media like Malt extract broth, Potato dextrose Broth, Czapeck Dox, Sabrourd's medium, Yeast glucose broth, Basal liquid media, Rose Bengal medium were screened for laccase production, Czapek Dox proved to be the best medium showing 17.2 $\mathrm{U} / \mathrm{ml}$ of laccase activity at $\mathrm{pH} 7.3$ and temperature $\pm 25^{\circ} \mathrm{C}$.

Janusz et al., (2006) in their studies, got significantly good laccase production using Czapek Dox and Linderberg -Holm medium on $11^{\text {th }}$ day and $8^{\text {th }}$ day of incubation in Rizoctonia praticola. Similarly Czapek Dox showed maximum laccase production in Cochliobous sp. isolated from plastic dumped soils by Tirupati et al., (2016).

Generally it is believed that Czapek Dox supports the growth of the organisms which are capable to utilize sodium nitrate as the sole source of nitrogen.

\section{Influence of carbon sources on laccase production}

Seven carbon sources like fructose, maltose, glucose, galactose, lactose, cellulose and sucrose which are present in control Czapek Dox medium were screen to find the most significant carbon source. Medium containing sucrose exhibited maximum enzymatic activity of laccase i.e. $19.3 \mathrm{U} / \mathrm{ml}$ followed by cellulose i.e., $14.7 \mathrm{U} / \mathrm{ml}$. In one of the study on Pycnoporus Sanguineus for production of laccase enzyme, the workers Eugenio et al., (2016) demonstrated effect of maltose, fructose, glucose and sucrose from which sucrose exhibited highest production of laccase. Results are also in accordance with a similar study carried out by Jose and Joel et al., (2014) on Agaricus sp. where highest yield was obtained in medium containing sucrose. The ability of the organism to give comparatively better result on cellulose demonstrates the possibility of presence of cellulase in the organism which enables organism to utilize cellulose present in the medium.

\section{Influence of nitrogen sources on laccase production}

Effect of different organic nitrogen sources like malt extract, urea, peptone and inorganic nitrogen sources like ammonium nitrate, sodium nitrate and ammonium chloride was studied on laccase production. Highest laccase activity of $18.6 \mathrm{U} / \mathrm{ml}$ was observed with sodium nitrate which is closely followed by ammonium nitrate i.e. $16.2 \mathrm{U} / \mathrm{ml}$. These results demonstrate the fact that Scytalidium lignicola can effectively utilize inorganic nitrogen sources containing nitrate. Sodium nitrate is also reported to have significant influence on laccase production by Muthukumarasamy et al., (2015). It was also found to be best nitrogen source for laccase production by Dictyoarthrinium synnematicum Somrith (Prasher et al., 2015). 
Fig.1 Oxidative polymerization of guaiacol to form reddish brown zones in the medium by Scytalidium lignicola

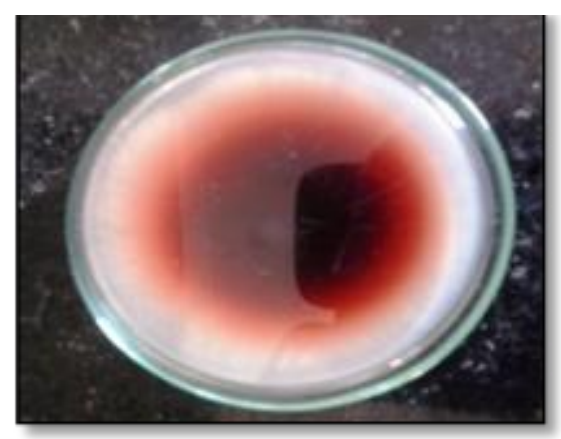

Fig.2 Blue color zones on medium containing ABTS by Scytalidium lignicola.

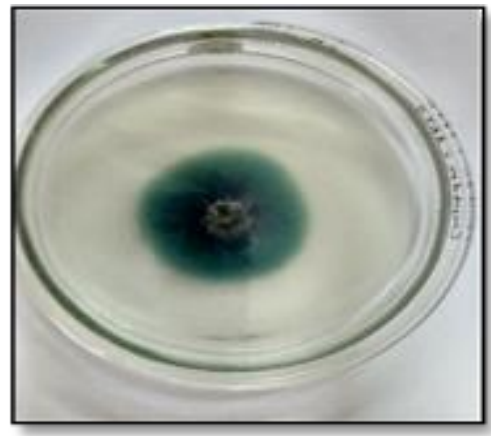

Fig.3 No clearence zone surrounding the colony of Scytalidium lignicola on Azure B containing plate. A.Top view of the plate, B.Inverted view of the plate
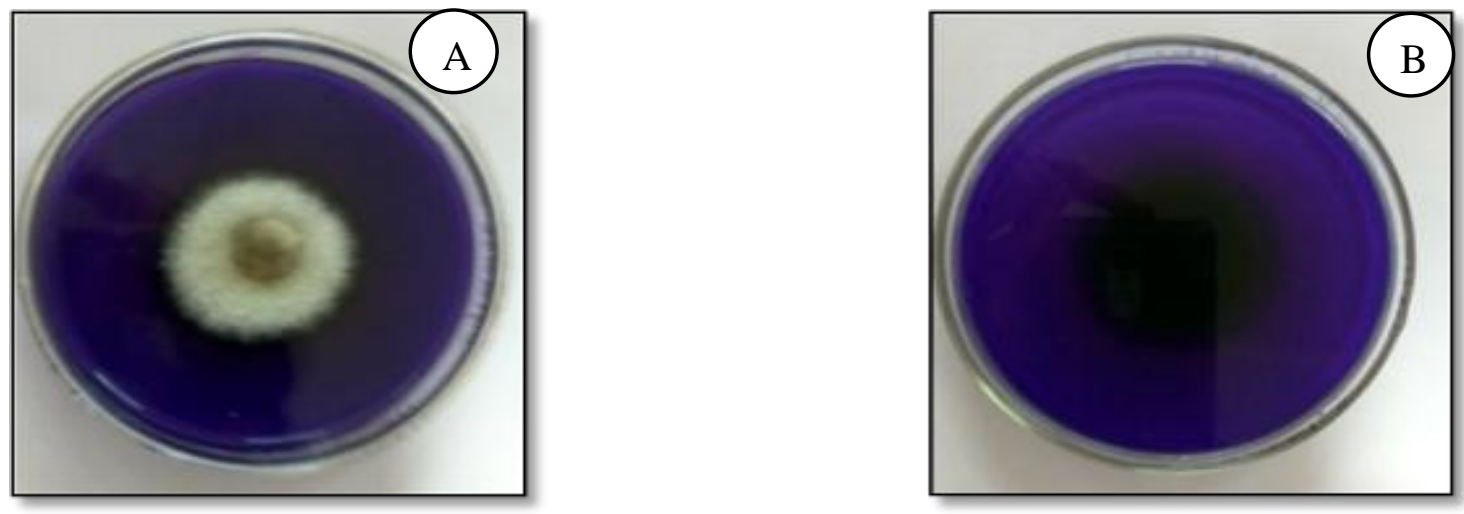

Graph.1 Graph displaying effect of different media on activity of enzyme produced under submerged condition

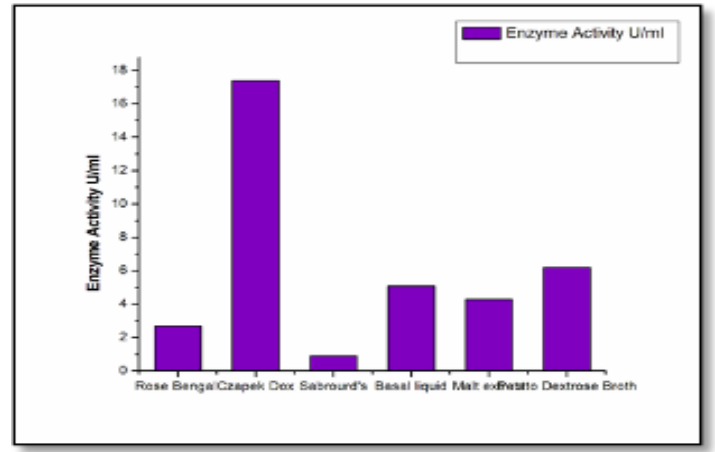


Graph.2 Graph displaying influence of different carbon sources on the activity of enzyme produced under submerged condition

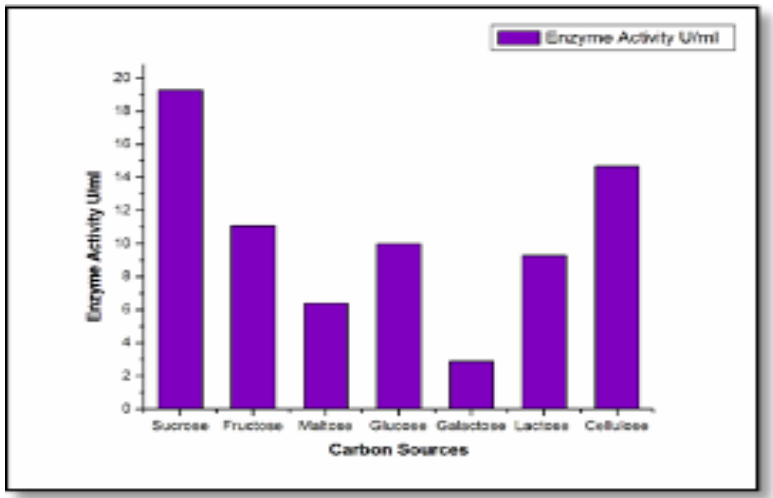

Graph.3 Graph displaying influence of different nitrogen sources on the activity of enzyme produced under submerged condition

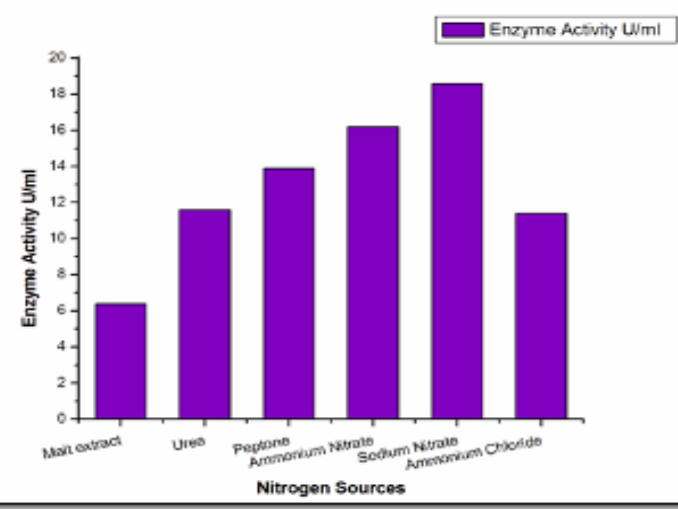

Graph.4 Graph displaying influence of $\mathrm{pH}$ on the activity of enzyme produced under submerged condition

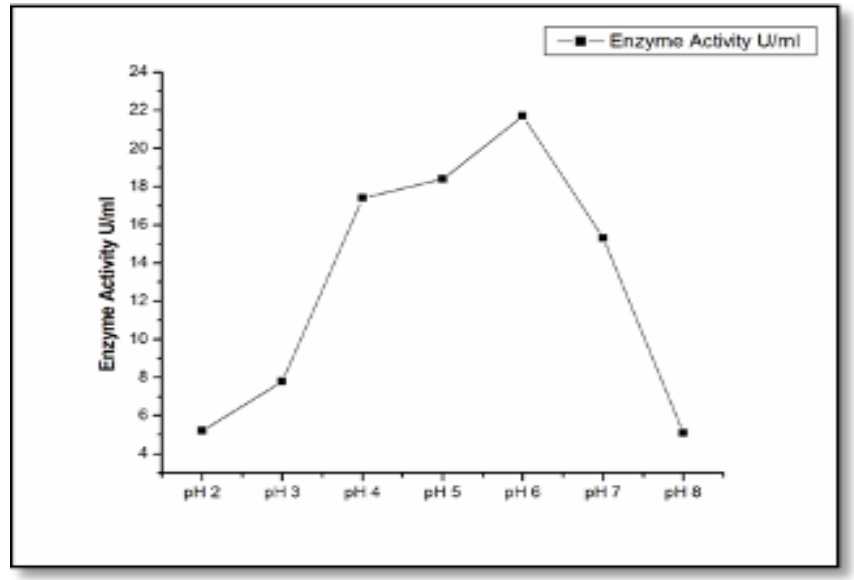


Graph.5 Graph displaying influence of temperature on the activity of enzyme produced under submerged condition

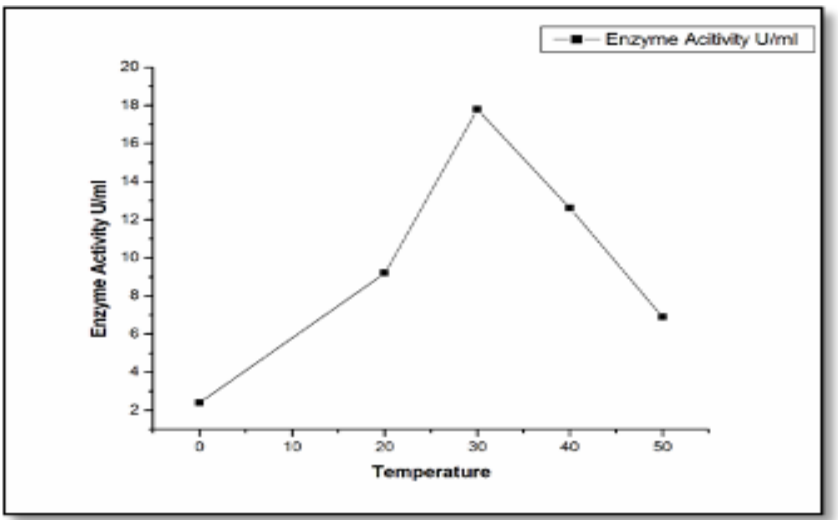

Graph.6 Graph displaying influence of inoculum size on the activity of enzyme produced under submerged condition

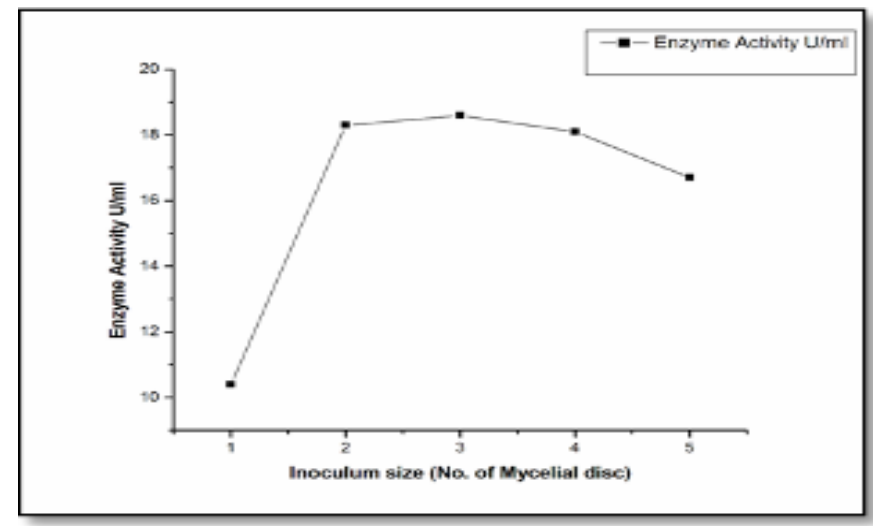

Graph.7 Graph displaying influence of incubation period on the activity of enzyme produced under submerged condition

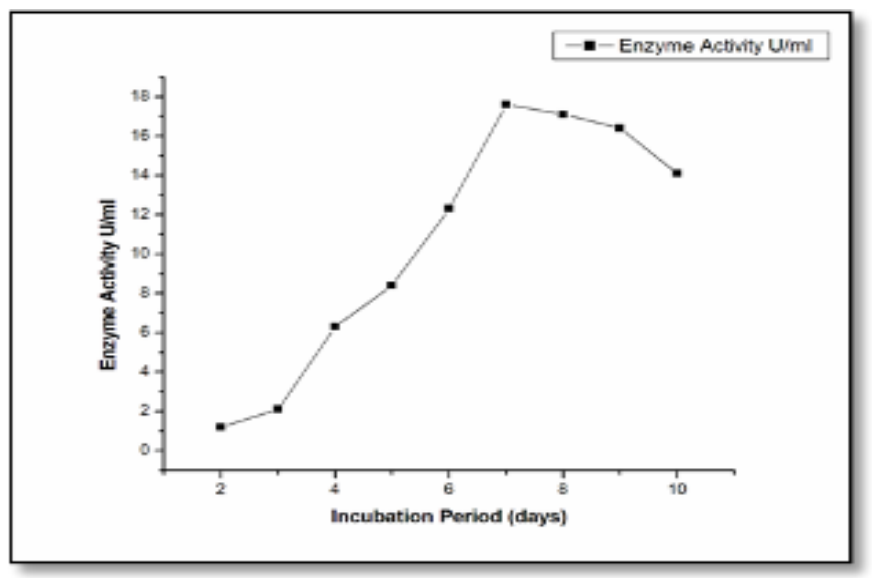


Graph.8 Graph displaying influence of different inducers on the activity of enzyme produced under submerged condition

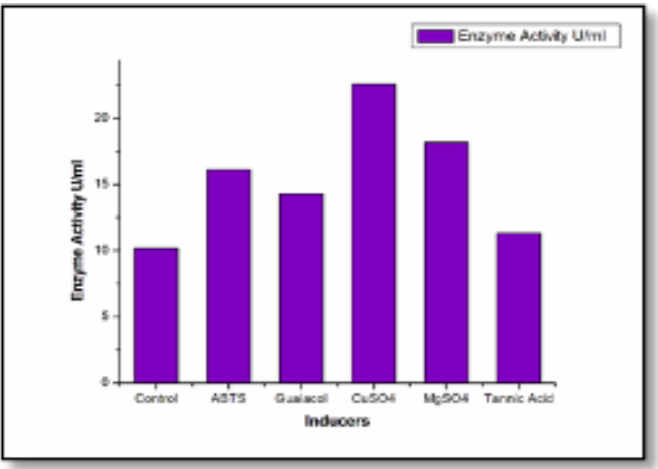

Graph.9 Graph displaying influence of $\mathrm{CuSO}_{4}$ on the activity of enzyme produced under submerged condition

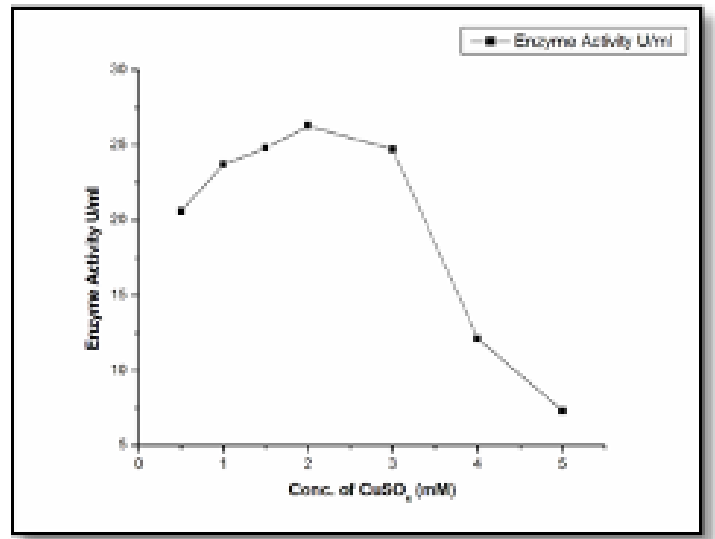

Graph.10 Graph displaying influence $\mathrm{MgSO}_{4}$ on the activity of enzyme produced under submerged condition

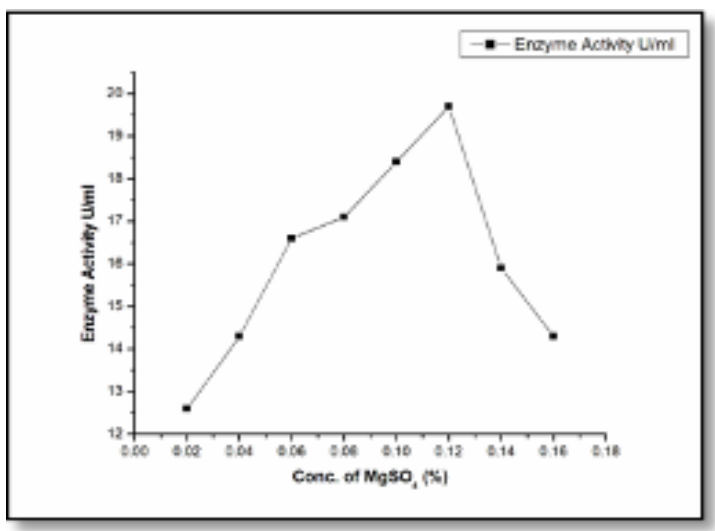


Graph.11 Graph displaying influence of different inhibitors on the activity of enzyme produced under submerged condition

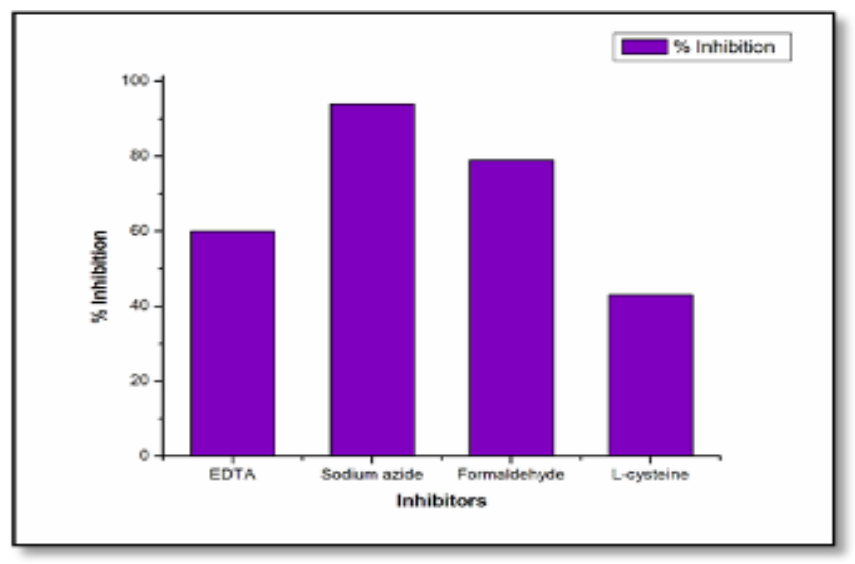

Influence of initial $\mathrm{pH}$ on laccase
production

There is high correlation between laccase production and changes in the medium $\mathrm{pH}$ during cultivation. In current study effect of $\mathrm{pH}$ ranging from $\mathrm{pH} 2$ to $\mathrm{pH} 8$ was studied on laccase production. It is observed that $\mathrm{pH} 4$, $\mathrm{pH} 5$ and $\mathrm{pH} 6$ are most influential for laccase production by the organism with $\mathrm{pH} 6$ showing maximum activity of the laccase i.e. $21.7 \mathrm{U} / \mathrm{ml}$. Most fungal laccase reach their maximum activity when the initial $\mathrm{pH}$ of the nutrient medium ranges from 4 to 6 (Janusz et al., 2006). The highest activity of laccase was observed at $\mathrm{pH}$ between 4.5 and 6.5, in Pleurotus osteatus (Nadeem et al., 2014). Also Sivakumar et al., (2010) reported highest laccase production at $\mathrm{pH} 5$ in case of Ganoderma sp.

\section{Influence of temperature on laccase production}

Study of effect of different temperature reveals that $30^{\circ} \mathrm{C}$ is the optimum temperatue for the laccase production by Scytalidium lignicola. The data obtained is in agreement with most of the other studies carried out to demonstrate the effect of temperature on laccase production. In the work done by Chenthamarakshan et al., (2017) on Marasmiellus palmivorus the maximum laccase production was observed at $28^{\circ} \mathrm{C}$ while $30^{\circ} \mathrm{C}$ gave better production of laccase in Pleurotus osteatus (Nadeem et al.,2014). Results obtained are similar to the results obtained by Risdianto et al., (2010) who got maximum laccase production by under solid state fermentation in between $25^{\circ} \mathrm{C}$ and $31^{\circ} \mathrm{C}$ by Marasmium sp. Normally, the fermentation processes ( $\mathrm{SSF}$ as well as $\mathrm{SmF}$ ) develop with mesophilic microbial strains (Risdianto et al., 2010). As Scytalidium lignicola also belongs to mesophilic organisms, the growth temperature is in the range of $20-40^{\circ} \mathrm{C}$.

\section{Influence of inoculum size on laccase production}

Inoculum size plays a significant role in any fermentation. A lower level of inoculum may not be sufficient to initiate the growth, whereas a higher level may cause competitive inhibition (Patel et al., 2009). Therefore determining exact inoculum size is critical step. To demonstrate the effect of inoculum size on laccae production, $100 \mathrm{ml}$ of Czapek Dox medium was inoculated with varying 
number of mycelial discs (Nos.1-5). Although there is slight increase in laccase activity with increasing inoculum size but the increase is not significant beyond 2 disc/100 medium. So, addition of two mycelial discs is sufficient to achieve the desired enzyme production.

\section{Influence of incubation period on laccase production}

Incubation period is a critical factor to be kept in mind for getting maximum productivity of the enzyme in shortest possible time at industrial scale. The broth was harvested everyday from day 2 to day 10 to determine proper incubation period necessary for obtaining maximum enzyme productivity. The production of laccase increased linearly with increasing incubation period up to day 7 where the enzyme activity was found to be $16.9 \mathrm{U} / \mathrm{ml}$. From day 7 onwards there was not substantial increase in enzyme activity which proves that incubation up to 7 days is sufficient to obtain maximum enzyme production.

\section{Influence of inducer on laccase production}

Interestingly, addition of some of the inducers resulted in strikingly enhanced production of laccase. The inducer employed were ABTS (0.6mM), Guaiacol (1mM), $\mathrm{CuSO}_{4}(2 \mathrm{mM})$, $\mathrm{MgSO}_{4}(0.1 \%)$ and Tannic acid $(0.2 \mathrm{mM})$. Although all the inducers applied resulted in enhanced activity of the laccase but the effect of copper was quite prominent when compared with other inducers. Addition of $\mathrm{CuSO} 4$ and $\mathrm{MgSO}_{4}$ to growth medium resulted in high production of laccase i.e. $22.6 \mathrm{U} / \mathrm{ml}$ and $18.2 \mathrm{U} / \mathrm{ml}$ respectively which is quite high as compared to the control i.e. $10.2 \mathrm{U} / \mathrm{ml}$. Copper is an essential micronutrient for the most living organisms, copper requirement by microorganism are usually satisfied in very low concentration, ranging between 1 to $10 \mathrm{mM}$. Copper present in higher concentration in its free cupric form is extremely toxic to microbial cells. Periasamy et al., (2011) studied the effect of different metal ions on laccase production, out of different metals $\mathrm{Hg}^{2+}, \mathrm{Cd}^{2+} \mathrm{Zn}^{2+}, \mathrm{Cu}^{2+}$, $\mathrm{Mn}^{2+}, \mathrm{Mg}^{2+}$ screened, $\mathrm{Cu}^{2+}$ was best for laccase production followed by $\mathrm{Mg}^{2+}$ in Pleurotus ostreatus. Kenkebashvili et al., (2012) reported that Coriolopsis gallia grown at $2.0 \mathrm{mM} \mathrm{Cu}^{2+}$ exhibited high laccase activity as compared to the culture grown at $0.5 \mathrm{mM}$ and $1 \mathrm{mM} \mathrm{Cu}{ }^{2+}$ concentration. In a study carried by Sel et al., (2015) $\mathrm{MgSO}_{4}$ at the concentration of $0.05 \%$ has shown significant influence on laccase production by Pleurotus ostreatus. Keeping in mind the importance of $\mathrm{Cu}^{2+}$ and $\mathrm{Mg}^{2}$ on laccase production, experiments were also carried out to find out the optimum concentration of both metal ions for the production of laccase. It can be observed from the data that $2 \mathrm{mM}$ of $\mathrm{CuSO}_{4}$ and $0.12 \%$ of $\mathrm{MgSO}_{4}$ is optimum for the laccase production by Scytalidium lignicola.

\section{Influence of inhibitors on laccase production}

The laccase production by Scytalidium lignicola was inhibited $94 \%$ in presence of $1 \mathrm{mM}$ sodium azide and $79 \%$ by formaldehyde conversely L-cysteine and EDTA had a relatively low inhibitory effect i.e., $43 \%$ and $60 \%$ respectively. These results are very similar to the previously reported laccase from Basidomycete Fomitella fraxinea (Mi et al., 2007). It is formerly reported that binding of sodium azide to the types 2 and 3 copper sites affects internal electron transfer, thus inhibiting the activity of laccase, also formaldehyde being an organic solvent is assumed to alter $\mathrm{pH}$ of aqueous solution resulting in reduced enzyme production (Tiwari and Chittora, 2013). EDTA is a metal ion chelating agent and can inhibit metalloprotease activity and L-cysteine is a strong reducing agent of disulphide bond 
between protein molecules (Xu et al., 2016). Laccase from $C$. thermophilium was also strongly inhibited by $\mathrm{Cu}$-chelating agents (Chefetz et al., 1998).

\section{Enzyme production under optimized conditions}

After optimizing all the above mentioned parameters the laccase enzyme production was carried out in modified Czapek Dox medium incorporating $2 \mathrm{mM} \mathrm{CuSO}_{4}$ and $1 \%$ $\mathrm{MgSO}_{4}$ as enzyme inducer and adjusted at initial $\mathrm{pH}$ 6. The sterilized medium was inoculated with 2 mycelial discs and incubated at $30^{\circ} \mathrm{C}$ for 7 days. The enzyme activity obtained under optimized conditions was $28.2 \mathrm{U} / \mathrm{ml}$ which is 1.5 folds of the enzyme activity obtained in control i.e. $17.4 \mathrm{U} / \mathrm{ml}$

\section{References}

Abaulla,E.,Tzanov,T.,Costa,S.,Robra,K.H.,Pa ulo,A.C.,Gubitz,G.M.,2000.Decoloriz ation and detoxification of textile dyes with a laccase from Trametes hirsuta. Applied and Environmental Microbiology. 66,3357-3362.

Alfarra, H.Y.,Kasali, N.H.M., Omar, M.N.,2013.Alignolytic fungi with laccase activity isolated from Malaysian local environment for phytochemical transformation purposes. Int.Res.J.Biological Sci.2(2),51-54.

Amutha,C.,Abhijit,M.,2015.Determination of optimal condition for growth, laccase production and choose the best strain. J. of Bioremed and Biodeg.6,298.

Bourbonnais,R.,Paice,M.G.,Reid,I.D,Lanthier ,P.,Yaguchi,M.,1995.Lignin oxidation by laccase isoenzymes from Trametes versicolor and role of mediator 2,2'Azinobis (3-Ethlbenzthiazoline-6Sulfonate) in kraft lignin depolymerization. Applied and Environ. Microbiol,1876-1880.

Chefetzl,B.,Chen,Y.,Hadar,Y.,1998.Purificati on and characterization of laccase from Chaetomium thermophilium and its role in humification. Appl.Environ, Microbiol.64,3175-3179.

Chenthamarakshan, A., Parambayil, N., Miziriya, N., Soumya, P.S.,Laksmi, M.S.K., Ramgopal, A.,Dileep, A., Nambisan, P.,2017. Optimization of laccase production from Marasmiellus palmivorours LA1 by Taguchi method of design of experiments.BMC Biotechnol.17:12

Christie,

S.A.D.,Shanmugam,S.,2012.Analysis

of fungal cultures isolated from Anamalai hills for laccase enzyme production, effect on dye decolorization, antimicrobial activity.Int.J.of Plant,Animal and Environ.Sci.2,143-148.

Desai, S.S., Tennali, G.B., Channur, N., Anup, A.C., Deshpande, G., Murtuz, B.P.A. 2011. Isolation of laccase producing fungi and partial characterization of laccase. Biotechnology, Bioinformatics, Bioengineering.1(4),543-549.

Ding, Z., Peng, L., Chen, Y., Zhang, L., Gu, Z., Shi, G., Zhang, K., 2012. Production and characterization of thermostable laccase from the mushrooom, Ganoderma lucidum, using submerged fermentation. African J. Microbiol.6(6),1147-1157.

EI-Zayat, S.A., 2008. Preliminary studies on laccase production by Chaetomium globosum an endophytic fungus in Glinus lotoiks. American-Eurasian J.Agric. and Environmental Sci, 3,8690.

Elsayed,M.A.,Hassan,M.M.,Elshafei,A.M.,Ha roun,B.M.,Othman,A.M.,2012.Optimi zation of cultural and nutritional 
parameters for the production of laccase by Pleurotus ostreatus ARC280.British Biotechnology Journal,2(3),115-132.

Eugenia,M.E.,Carbajo,J.M.,Martin,J.A.,Gonz alez, A.E., Villar,J,C.,2009. Laccase production by Pycnoporus sanguineus under different culture conditions. J.Basic Microbol.49(5),433-440.

Fu,K.,Fu,S.,Zhan,H.,Zhou,P.,Liu,M.,Liu,H.,2 013.A newly isolated wood-rot fungus for laccase production in submerged cultures.BioResources.8,1385-1397.

Iyer,G.,Chattoo,B.B.,2003.Purification and characterization of laccase from the rice blast fungus, Magnaporthe grisea. FEMS Microbiol. letters.227,121-126.

Janusz,G.,Rogalski,J.,Barwinska,M.,Szczodra k, J.,2006.Effect of culture conditions on production of extracellular laccase by Rhizoctonia praticola.Polish J. of Microbiol.55,309-319.

Jose, L.J.,Joel,G.J.,2014.Optimization of culture conditions for improved laccase production by Agaricus sp.LCJ262. Int.J.Current Research ,6 (11),9517-9522.

Kameshwar,A.K.S.,Qin,W.,2016.Qualitative and quantitative methods for isolation and characterization of ligninmodifying enzymes secreted by microorganisms. Bioenerg. Res. 97845.

Kenkebashvilli,N.,Elisashvili,V.,Wasser,S.P., 2012.Effect of carbon, nitrogen sources and copper concentration on the lignolytic enxyme production by Coriolopsis gallica.J.Waste Conver, Bioprod.Biotechnol.1(2),22-27.

Kiiskinen,L.L.,Ratto,M.,Kruus,K.,2004.Scree ning of novel laccase-producing microbes. J. of Applied Microbiol.,97,640-646.

Kumar,R.,Kaur,J.,Kumar,A.,2016.Optmizatio $\mathrm{n}$ of laccase production from Aspergillus flavus by design of experiment technique: partial purification and characterization.J.Genetic Engi.Biotechnol.14(1), 125-131.

Li,A.,Zhu,Y.,Xu,L.,Zhu,W.,Tian,X.,2008.Co mparitive study on the determination of assay for laccase of Trametes sp. African J.Biochem. Research.2(8), 181-183.

Mahmoud,M.G.,Rifaat,H.M.,Ei Sayed,O.H., Ei Beih,F.M., Selim,M.S.,2013.Effect of inducers and process parameters on laccase production by locally isolated marine Strptomyces lydicus from Red Sea, Egypt.Int. J. Chem Tech. Research.5,15-23.

Majolagbe,O.,Oloke,J.,DekaBoruah,H.,Adetunji,C.,Bordoloi,A.,Bo rah,M.,2012.Extraction and purification of extracellular laccase from wild,mutants and hybrid strains of two white-rot fungus and its application in decolourization and lignolysis. J. Microbiol,Biotechnol. Food Sci.2(3),998-1016.

Manimozhi,M.,Kaviyarasan,V.,2012.Screenin $\mathrm{g}$ the effect of nutritional parameters on biomass and laccase production in submerged medium by litter decomposing Basidiomycete Agaricus heterocystis. Int.J.Pharm. Pharm.Sci. 4(3), 592-599.

Mi,P.K.,Park,S.,2007.Purification and characterization of laccase from Basidiomycete Fomitella fraxinea. J.Microbiol.Biotechnol.18(4),670-675.

More,S.S.,Renuka,P.S.,Pruthvi,K.,Swetha,M., Malini,S.,Veena,S.M.,2011.Isolation, purification, and characterization of fungal laccase from Pleurotus sp.Enzyme

Research,10.4061/2011/248735.

Muthukumarasamy,N.P.,Jakson,B.,Antony,J. R.,Sevanan,M.,2015.Production of extracellular laccase from Bacillus subtilis MTCC2414 using agro 
residues as a potential substrate. Biochem. Res. Int.765190.

Nadeem,A.,Baig,S.,Sheikh,N.,2014.Mycotech nological production of laccase by Pleurotus ostreatus-P1 and its inhibition study.J.Ani.Plant Sci.24(2),492-502.

Patel,H.,Gupte,A.,Gupte,S.,2009.Effect of different culture conditions and inducers on production of laccase by a Basidiomycete fungal isolate Pleurotus ostreatus HP-1 under solid state fermentation. BioResources. 4(1), 268-284.

Patrik, F., Mtui, G., Mshandete, A.M., Johansson, Livaisi A. 2009. Purification and characterization of a laccase from the basidomycete Funalia trogii (Berk.) isolated in Tanzania. African J. Biochem. Research. 3(5),250-258.

Periasamy,R.,Rajadurai,M.,Palvannan,T.,201 1.Effect of different agro-wastes on laccase production by Pleurotus ostreatus IMI 395544. Int. J. Environ. Sci. Ecotechnol., 1(1), 21-26.

Prasher, I.B., Chauhan, R., 2015. Effect of carbon and nitrogen sources on the growth,reproduction and ligninolytic enzymes activity of Dictyoarthrinium synnematicum Somrith. Adv. Zool. Bot., 3(2): 24-30.

Rajendran, K., Annuar, M.S.M., Karim, M.A.A., 2011.Optimization of nutrient level for laccase fermentation using statistical techniques. J. Mol. Biol. Biotechnol., 19(2),73-81.

Risdianto, H., Suhardi, S.H., Setiadi, T., Kokugan, T., 2010.The influence of temperature on laccase production in solid state fermentation by using white rot fungus Marasmius sp.The $1^{\text {st }}$ International Seminar on Fundamental and Application of Chemical Engineering. A009:1-6.
Saito T, Hong P,Kato K, Okazaki M, Inagaki $\mathrm{H}$, Maeda S, Yologawa Y. Purification and characterization of an extracellular laccase of a fungus (family Chaetomiaceae) isolated from soil. Enzyme and Microbial Technology 2003,33:520-526.

Saparrat,M.C.N.,Arambarri,A.M.,Balatti,P.A., 2007.Growth and extracellular laccase production in liquid cultures of Minimidochium parvum LPSC\#548 strain.Bio.Soc.Argent.Bot.42,39-44.

Sel,N.B.,Gregori,A.,Leitgeb,M.,Klinara,D.,Ce lan,S., (2015). Effect of solid state fermentation medium optimization on Pleurotus ostreatus laccase production. Acta Chimica Solovenica.62(4),932-939.

Sheikhi,F.,Ardakani,M.R.,Enayatizamir,N.,R odriguez-Couto,S.,2012.The determination of assay for laccase of Bacillus subtilis WPI with two classes of chemical compounds as substrates.Indian J.Microbiol.54,701707.

Sidhu,A.K.,Agrawal,S.B.,Sable,V.,S.,Patil,S. N.,Gaikwad,V.B.,2014.Isolation of Colletotrichum gloeosporioides gr., a novel endophytic Laccase -producing fungus from the leaves of a medicinal plant, Piper betle. Int. J. Scientific and Engi. Research 5(2)1087-1098.

Singh,N.,Abraham,J.,2013.Isolation of laccase producing fungus from compost soil and partial characterization of laccase.Adv.Appl.Sci.Res.4(5).91-98.

Sivkumar,R.,Rajendran,R.,Balakumar,C.,Tam ilvendan,M.,2010.Isolation,screening and optimization of production medium for thermostable laccase production from Ganodema sp. Int.J.Engi.Sci.Tech.2(12),7133-7141.

Thruston CF. The structure and function of fungal laccases. Microbilogy 1994,140:19-26. 
Tirupati,S.,Viswanath,B.,Lakshmi,A.S.,SaiGo pal,D.V.R.,2016.Production of laccase by Cochliobolus sp.isolated from plastic dumped soils and their ability to degrade low molecular weight PVC.Biochem.Res.Int.9519527.

Tiwari,G.K.,Chittora,M.,2013.Study the effect of various physical and biochemical parameters on the production of laccase enzyme produced from Aspergillus flavus at in vitro conditions. Int.J.Recent Scientific Research,4(5),662-665.

Xu,Y.,Lu,Y.,Zhang,R.,Wang,H.,Liu,Q.,2016. Characterization of a novel laccase purified from the fungus Hohenbuehelia serotina and its decolourtisation of dyes. Acta ABP Biochimica Polonica.63(2),273-279.

Zhu C, Bao G,Huang S.2016.Optimization of laccase production in the white-rot fungus Pleurotus ostreatus (ACCC52857) induced through yeast extract and copper. Agriculture and Environmental Biotechnology, 30(2)270-276.

Zouari-Mechichi, H., Mechichi, T., Dhouib, A., Sayadi, S., Martinez, A.T, mMartinez, M.J., 2005. Laccase purification and characterization from Trametes trogii isolated in Tunisia: decolorization of textile dyes by the purified enzyme. Enzyme Microbial Tech,39,141-148.

\section{How to cite this article:}

Amanpreet K. Sidhu, Sonali B. Darade, Praneeta P. Bhavsar, Vishwas B. Gaikwad and Sucheta N. Patil. 2017. Isolation, Screening and Optimization for Laccase production by Scytalidium lignicola pesante under submerged fermentation. Int.J.Curr.Microbiol.App.Sci. 6(4): 24772491. doi: https://doi.org/10.20546/ijcmas.2017.604.289 